\title{
PESQUISA PSICANALÍTICA DE FENÔMENOS SOCIAIS NA UNIVERSIDADE: POTENCIALIDADE POLÍTICA NA SUBVERSÃO DOS DISCURSOS
}

\author{
PSYCHOANALYTIC RESEARCH ON SOCIAL PHENOMENA IN \\ UNIVERSITY: POLITICAL POTENTIALITY WITHIN SUBVERSION OF \\ DISCOURSES
}

\author{
Omar David Moreno Cárdenas ${ }^{1}$ \\ Andréa Máris Campos Guerra²
}

\begin{abstract}
Resumo: Este artigo explora consequências epistemológicas e políticas de se realizar pesquisa de fenômenos sociais com um olhar psicanalítico dentro da universidade, tanto para a psicanálise, o campo social e a própria universidade. No início estabelecemos a relação entre ciência e psicanálise, o que nos permite refletir sobre a participação da psicanálise na universidade e as tensões clássicas desse intercambio. Em seguida, apresentamos o impasse de se pesquisar fenômenos sociais com a psicanálise face à indissociabilidade de teoria, método e clínica. Nossa chave de leitura é a teoria dos discursos da psicanálise lacaniana, indicando o potencial político dessa modalidade de pesquisa ao causar subversões nas formas de poder e dominação discursiva na universidade, nas instituições de psicanálise e no campo social.
\end{abstract}

Palavras-chave: Fenômenos sociais; Pesquisa psicanalítica; Teoria dos discursos; Psicanálise; Subversão.

\begin{abstract}
This paper explores the epistemological and political consequences of conducting research on social phenomena from a psychoanalytic perspective within the university, for the psychoanalysis, the social field and the university. In the beginning, we established the relationship between science and psychoanalysis, which allows us to reflect on the psychoanalysis participation in the university and the classic tensions of this exchange. Next, we present the impasse of researching social phenomena from the psychoanalysis taking in account the indissociability between theory, method and clinic. Our theoretical perspective is the discourses theory of Lacanian psychoanalysis, indicating the political potential of this research modality by causing subversions in the forms of power and discursive domination in the university, in the institutions of psychoanalysis and in the social field.
\end{abstract}

Keywords: Social phenomena; Psychoanalytical research; Discourses theory; Psychoanalysis; Subversion.

\section{Introdução}

Este artigo visa reconhecer a importância de se discutir a relação entre ciência e psicanálise bem como as implicações que essa reflexão tem quando se introduz um olhar

\footnotetext{
${ }^{1}$ Psicólogo, Universidad del Valle. Mestrando em psicologia na área de estudos psicanalíticos (Bolsista CAPES) pela Universidade Federal de Minas Gerais (UFMG). Colaborador do Núcleo de Psicanálise e Laço Social Contemporâneo (PSILACS) da UFMG, Belo Horizonte, Minas Gerais, Brasil. E-mail: davidmc.90@hotmail.com

${ }^{2}$ Psicanalista, psicóloga e advogada. Doutora em teoria psicanalítica pela Universidade Federal de Rio de Janeiro (UFRJ). Professora do departamento de psicologia da UFMG. Coordenadora do Núcleo de Psicanálise e Laço Social Contemporâneo (PSILACS) da UFMG, Belo Horizonte, Minas Gerais, Brasil. Email: andreamcguerra@gmail.com
} 
clínico-psicanalítico na pesquisa de fenômenos sociais. Entendendo a psicanálise como marco de leitura que incide sobre práticas clínicas, como campo autônomo (psicanálise pura) e, na área da psicologia clínica, como uma perspectiva de abordagem; partimos da perspectiva de que o campo de pesquisa da psicanálise tem sempre um olhar clínico, ainda quando a pesquisa se desenvolva por fora da experiência clínica, caso dos fenômenos sociais.

De partida, reconhecemos que a relação entre ciência e psicanálise é marcada por conflitos que possibilitaram encontros e desencontros que revelam uma dinâmica de tensões de corte político e epistemológico. Reconhecemos, a partir dessa tensão, uma potencialidade política da psicanálise como um discurso particular dentro da universidade. Além disso, consideramos que a pesquisa de fenômenos sociais na psicanálise introduz uma variável adicional, ao ser uma possibilidade de submeter à análise as limitações do discurso capitalista no laço social contemporâneo. Explicaremos.

A presença da psicanálise nos meios universitário e científico mundiais mostra um desenvolvimento muito diverso a depender do país e da região. Essa diversidade poderia nos auxiliar a entender o fundo político e epistemológico que possibilita à teoria e ao discurso psicanalítico proliferarem em alguns contextos acadêmicos e em outros estar praticamente inexistente. Nos Estados Unidos, Inglaterra, Canadá, Austrália, Alemanha, Espanha e uma grande parte dos países do resto da Europa, o ensino da psicanálise na universidade não se apresenta mais dentro do escopo curricular obrigatório da seção de psicologia clínica ou de psiquiatria (HALE, 1995). Por outro lado, na Argentina, Brasil, França e alguns outros países latino-americanos, a psicanálise está representada em disciplinas da grade curricular dos cursos de psicologia. No caso especial da Argentina, é conhecida a alta incidência da psicanálise na cultura popular e sua consolidação como uma prática clínica de alta demanda, retomando a história da inserção psicanalítica nesse país (ARBISER, 2003). No Brasil, por exemplo, existem vinte e um programas de pósgraduação no campo da psicologia em nível de mestrado e/ou doutorado que incluem linhas e áreas de concentração em psicanálise (CAPES, 2016).

Em países latino-americanos como Colômbia, Venezuela, México, Chile e Uruguai contempla-se o ensino da psicanálise no nível de graduação em psicologia como um enfoque, escola ou teoria dentro da psicologia clínica. A presença de programas de mestrado e doutorado em psicanálise nesses países existe de forma mais discreta e com menos opções, mas considera-se um campo de pesquisa profissional. 
Como entender a diversidade na consolidação da psicanálise, como clínica e como marco de referência teórico-acadêmico, no mundo? Parece que a psicanálise tem construído um lugar forte como clínica, instituição e pesquisa acadêmica na Argentina, no Brasil e na França, apresentando um desenvolvimento mais discreto e focado como perspectiva teórica no âmbito da psicologia clínica nos outros países latino-americanos e com pouca presença no resto do mundo. Nesse ponto, supomos, as tensões políticas e epistemológicas são tramitadas com maior facilidade nos lugares onde a psicanálise tem uma presença importante. Além disso, ao se estender ao campo político e mesmo ser retomada nesses países como fonte de investigação de fenômenos sociais e políticos, carece retomarmos a discussão epistemológica que contorna essa presença, buscando verificar suas consequências.

Retomando algumas colocações de Freud e Lacan acerca da psicanálise na sua relação com a ciência, a proposta de Lacan no O Seminário 17. O avesso da psicanálise, no qual ele propõe pensar o laço social como um discurso, e a reflexão contemporânea de alguns pesquisadores em estudos psicanalíticos sobre a situação atual da psicanálise em relação à ciência, retomaremos a pergunta sobre as tensões e potencialidades políticas e epistemológicas que podem se extrair da inserção da psicanálise na universidade, especificamente na pesquisa de fenômenos sociais.

Nas linhas que seguem, problematizaremos a relação entre psicanálise e ciência, pensando as noções de ciência e de verdade para a psicanálise e explicitando algumas tensões clássicas quando se encontram a psicanálise, a ciência e a universidade num mesmo projeto. Apresentaremos o problema de pesquisar fenômenos sociais a partir da psicanálise quando temos no horizonte a indissociabilidade entre método, clínica e teoria. Numa segunda aproximação, questionaremos as consequências metodológicas, epistemológicas e políticas de se pesquisar fenômenos sociais com uma mirada clínica a partir da psicanálise. Para isso é preciso introduzir a proposição do laço social como discurso apresentada por Lacan como estratégia para pensar as questões políticas. Essa discussão prévia nos leva a sustentar que essa forma de pesquisa subverte os discursos dentro da universidade, das instituições de psicanálise e do contexto social, encontrando nessa subversão uma potencialidade política para questionar formas hegemônicas de fazer ciência e construir métodos.

\section{Psicanálise, ciência e universidade}


Sempre que se interroga a cientificidade da psicanálise, aos leigos, a questão em si parece pouco interessar. A preocupação do senso comum gravita em torno da eficácia da clínica (o que sempre parece instalar-se em um horizonte distante), aos cientistas quem eles seriam hoje? -, a questão é clara, a psicanálise se situa entre o místico e o saber intuitivo, dada a imaterialidade e antiempirismo de seu objeto (o inconsciente). Aos colegas psicólogos ainda resta uma suspeita, afinal como a psicanálise ainda se mantém no campo cientifico, acadêmico e profissional até hoje com os mesmos recursos românticos da Viena positivista do século retrasado?

Os psicanalistas, por sua vez, no interior de seu campo, nunca foram tomados pela dúvida. Sabem que trazem a peste (FREUD, 1909-10/1976), que ela excede a possibilidade sempre previsível, mas nunca alcançada, de se obter a verdade (que não é o mesmo que o saber) e seguem pelo rigor do método psicanalítico. Não cedem em palavras, nem em conteúdo, como já defendia Freud (1921/1976):

\footnotetext{
Não quis fazê-lo [trocar o termo sexual por erótico], porque me apraz evitar fazer concessões à pusilanimidade. Nunca se pode dizer até onde esse caminho nos levará; cede-se primeiro em palavras e depois, pouco a pouco, em substância também. [...] aquele que sabe esperar não precisa fazer concessões (FREUD, 1921/1976, p. 117)
}

Freud compreendeu a dimensão incalculável da conduta humana e a perspectiva imprevisível das fontes e vias de satisfação, encontrando na compulsão à repetição um antagonismo interno ao próprio sujeito: ele pode escolher o pior. O conceito de pulsão, entendida brevemente como um correlato anímico principalmente endógeno que impulsiona a atividade psíquica e que procura satisfação sexual, levou Freud a constatar de que não se faz norma, nem sistema, nem domesticação do gozo (o modo singular como o sujeito lida com a falta constitutiva por meio da repetição de insatisfações) sem efeitos civilizatórios evidentes e, com isso, se extrai conceito, teoria e práxis. Nesse ponto, Freud e Marx se aproximam ao proporem, ambos, uma posição de suspeita positiva em relação à realidade empírica observada. Ao lado de Nietzsche, compõem o trio denominado por Ricoeur (1978) de "mestres da suspeita moderna", por criticarem o império da razão suficiente, suspeitando da capacidade racional do ser humano em dar conta da existência e da realização humanas efetivas.

Nietzsche percebe que a racionalidade moderna, o apolíneo, se encontra em oposição aos instintos, à vida, ao dionisíaco, o que impossibilita o desenvolvimento da vida humana (RICOEUR,1978). A ideia de vontade de potência subverte a razão, para Nietzsche. A vontade não está fora do mundo, ela se dá na relação, ou seja, é múltipla e 
se mostra como efetivação real (RICOEUR,1978). Sendo assim, o mundo seria esta luta constante, sem equilíbrio possível, apenas tensão que se prova pelo movimento, às vezes delicado, outras vezes violento. Marx se faz mestre da suspeita ao constatar, em sua análise sociológica, que o projeto moderno ao visar, com ardor, a autonomia e emancipação do homem, acabou por produzir uma sociedade desumana, dominada pela lógica da economia capitalista (RICOEUR,1978). Freud, por sua vez, ao evidenciar o domínio das pulsões e a determinação inconsciente, retira o homem racional da condição de ser senhor em sua própria morada, produzindo um golpe narcísico contundente na crença moderna da liberdade e da autodeterminação (RICOEUR,1978). Nessa posição de suspeita, os três supõem que a realidade não se dá a ver diretamente, mas exige um trabalho de pensamento, de interpretação, de tradução, embasado na teoria e na experiência com a realidade, que inclui seus elementos não visíveis, não representáveis e nem sempre verificáveis empiricamente.

Dito isto, fica claro que a psicanálise põe dúvida à razão humana e faz dela uma premissa fundamental do seu escopo teórico, localizando-se no campo da pesquisa qualitativa e em uma tensão de entrada com a ciência dominante que procura por evidência, materialidade de objeto e demonstração experimental. Partindo disso, como Freud e Lacan - principais autores da psicanálise que sustentaram a prática de pesquisa e clínica que conduzimos- conceberam a relação entre ciência e psicanálise?

Comecemos com Freud. Em 1932, Freud (1933a/1976) proferiu uma conferência denominada, em português, A questão de uma Weltanschauung. Nela, Freud expressa que uma Weltanschauung "é uma construção intelectual que soluciona todos os problemas de nossa existência... com base em uma hipótese superior dominante" (FREUD, 1933a/1976, p. 193). Em consequência, ela "não deixa nenhuma pergunta sem resposta", nela "tudo o que nos interessa encontra seu lugar fixo" (FREUD, 1933/1976, p.193). Num recurso retórico de comparação, ele estabelece que a religião tem uma Weltanschauung, mas a diferencia da ciência, pois a Weltanschauung religiosa está fechada, seria uma cosmovisão prescrita, autodeterminada e sem possibilidade de crítica. Na ciência, essa visão do mundo ainda está em construção e permanece aberta.

Freud (1933a/1976) expressa que a ciência procura evitar fatores individuais e influências afetivas, tem um esforço de chegar à correspondência com a realidade. Com isso, pode-se inferir que, apesar de Freud assentar bases para se fundar uma suspeita na razão humana, a epistemologia que sustenta a proposta de Freud, ainda sendo subversiva, era a mesma que sustentava a física no começo do século passado. Apesar de considerar 
a psicanálise um arcabouço inacabado, incapaz de constituir uma Weltanschauung própria, isso não impediu que o campo psicanalítico encontrasse seus fundamentos conceituais e teóricos indispensáveis. Prova viva da postura freudiana de fidelidade ao acontecimento que produziu a psicanálise enquanto teoria e prática foram as secessões, como, por exemplo, a de Jung e a de Adler (FREUD, 1914/1976) ao longo da constituição de seu campo.

Freud (1933b/1976) aponta a necessidade da psicanálise ser tomada como unidade, reiterando a impossibilidade daquele que fala em nome dela de abrir mão do que se estruturou como conceitos fundamentais. Isso porque entendia que muitos dos que afirmavam usar a psicanálise em sua prática não a admitiam como um todo, ao que adverte: “embora a estrutura da psicanálise esteja inacabada, ela apresenta [...] uma unidade da qual elementos componentes não podem ser separados ao capricho de qualquer um" (FREUD, 1933b/1976, p. 137). E assevera:

\section{A atividade psicanalítica é árdua e exigente; não pode ser manejada como um par de óculos que se põe para ler e se tira para sair para caminhar. Via de regra, a psicanálise possui um médico [psicanalista] inteiramente, ou não o possui em absoluto (FREUD, 1933b/1976, p. 150).}

Foi assim que Silva (2012) concluiu uma pesquisa, assinalando o quanto a psicanálise, mesmo quando considerada aplicada, não o é se se afasta de seus fundamentos, assim também, podemos acrescentar, o é quando faz (sua) ciência. Em Freud, esses fundamentos estariam assentados na teoria da sexualidade, da libido, do inconsciente e da pulsão. É nesse sentido que "as aplicações da psicanálise são, também, sempre confirmações dela" (FREUD, 1933b/1976, p. 146).

Lacan (1964/1998a) menciona como acontecimento freudiano a descoberta que renova a teoria do inconsciente em seu período histórico e que funda uma nova concepção de ser humano na história das ideias. Ele acredita que Freud faz furo no discurso universal, porque inaugura uma nova concepção sobre o sujeito; depois dela não é possível mais abordar o sujeito da mesma forma com que se fazia antes. Nesse sentido, a noção de inconsciente tem o valor de um trauma, ela escreve um antes e um depois, ao mesmo tempo em que funda um elemento irreparável e inapreensível para sua época e mesmo para a que a sucedeu, esbarrando com o limite do saber. A ciência tradicional da época de Freud não conseguiu inscrever essa descoberta em seu texto oficial. Repudiou a psicanálise, acusou-a de pansexualista, mística e a-científica. A peste freudiana, malgrado os esforços de seus oponentes, porém, vingou e se proliferou. 
Sua prova teórica mais evidente é a análise de Lacan (1966/1998b), em A Ciência e a Verdade, texto no qual busca estabelecer, em seu tempo e já amadurecida sua interpretação de Freud, o lugar da psicanálise entre as ciências. Parte da discussão do estatuto de sujeito na psicanálise para interrogar sua condição de possibilidade, conferida pelo método cartesiano (claro, distinto, limpo e perfeito) no nascimento do período moderno.

Segundo Stengers e Chertok (1989), Lacan (1966/1998b) propõe à psicanálise interrogar a verdade da própria ciência, e não mais apenas do sujeito do inconsciente como Freud fizera. Lacan interpreta Freud como um acontecimento traumático, discute a cientificidade das ciências humanas e assinala o corte epistemológico que a linguística estabeleceu, definindo as bases para a discussão científica de uma série de disciplinas antes ditas humanas, sem fundamento epistemológico reconhecido. Lacan se encontra, assim, no interior do projeto epistemológico estruturalista francês, central ainda hoje para a análise da cientificidade desse campo.

Alguns elementos se destacam em sua argumentação: a crítica às ciências humanas baseadas na evidência, na essência ou no comportamento humano, sua proposição conceitual do objeto $a^{3}$ : para "integração correta da função, no tocante ao saber e ao sujeito, da verdade como causa" (LACAN, 1966/1998b, p. 890), a distinção entre saber e verdade, colocando em discussão o que seria o verdadeiro, na medida em que o sujeito está em "uma exclusão interna a seu objeto" (LACAN, 1966/1998b, p. 875), e a proposição de um programa de trabalho.

Lacan (1966/1998b) interroga a magia, a religião, a ciência e a psicanálise, a partir da filosofia aristotélica, fazendo corresponder à magia, a causa eficiente; à religião, a causa final; à ciência, a causa formal; e à psicanálise, a causa material, apontando os desvios de cada uma delas e sugerindo para a psicanálise uma direção de trabalho face à interpretação da própria ciência em relação a sua causa. Tomando a premissa freudiana de que uma Weltanschauung psicanalítica é desnecessária e impossível, Lacan acrescenta

\footnotetext{
${ }^{3} \mathrm{O}$ objeto $a$ é um conceito utilizado na obra lacaniana para indicar uma perda estrutural do sujeito. Nos processos de alienação e separação, o objeto $a$ é uma condição que permite a separação do sujeito da alienação com sua referência de alteridade; o sujeito reconhece que tanto ele como o Outro carecem de algo, e isso permite constituir a presença do desejo dos dois (LAURENT, 1997). Ao mesmo tempo, isso faz referência às formas parciais nas quais o sujeito encontra satisfação na relação com seu semelhante (cuidador, referente simbólico), formas de satisfação que se perdem em paralelo com a percepção que a criança tem dos furos dessa instancia de alteridade, furos que permitem reconhecer que no Outro (instância de alteridade) há desejo (RABIVONICH, 1993). Em síntese, podemos entender o objeto a como "o resto no sentido verdadeiro do termo: algo que vem nos lembrar do fato que não estamos representados, de que existe um limite, de que existem apenas representações parciais" (LAURENT, 1997, p. 41)
} 
o fato de que o ponto de operacionalidade ou de partida para a pesquisa psicanalítica, disjunto o saber da verdade, é exatamente esse em que um obstáculo ao saber se impõe, em que um vazio se instala onde a teoria justificava uma resposta, seja em relação a um impasse teórico, seja em relação a algum impasse clínico (LACAN, 1966/1998b), seja em relação a um impasse político-social, podemos acrescentar.

Com Freud, a psicanálise se inseriria na Weltanschauung da ciência pois não precisa constituir uma própria. Com Lacan, essa inserção precisa de uma especificidade ao levar em conta o significante como algo não redutível à prescrição de sentido. E Lacan, valeu-se do recurso linguístico para formalizar uma maneira de entender a psicanálise. Para ele, "não há ciência do homem porque o homem da ciência não existe, mas apenas seu sujeito" (LACAN, 1966/1998b, p. 873), afirma radicalmente. Ele acrescenta, que a ciência não tem memória, pois esquece os impasses em que nasceu. Para ele, o objeto da psicanálise deverá ser buscado na função que o objeto $a$ apresenta a partir do falo, como significante da falta simbólica - não como pênis -, lembrando que os psicanalistas devem resistir a qualquer modo de verdade como causa. Isto quer dizer que o objeto da psicanálise é o que representa o objeto $a$; a divisão do sujeito causada pela experiência com o inconsciente que marca uma perda irrecuperável e a impossibilidade do sujeito de recobrir toda a experiência do inconsciente com a linguagem.

Lendo Lacan, pensamos que no seu pensamento existe uma divergência entre ciência e psicanálise, encontrando que a psicanálise e a ciência se fundamentam sobre formas distintas abordagem do saber, a ciência aproximando saber e verdade e a psicanálise estabelecendo os limites e impossibilidades da verdade como causa. Embora a atuação e as consequências da teoria lacaniana possuam uma importante ressonância na produção de conhecimento acadêmico psicanalítico que acontece na universidade. E apesar da resistência de Lacan em conceber a psicanálise dentro do campo da ciência, os impasses históricos têm permitido que a psicanálise se inclua no marco científico e acadêmico hoje em dia e que seja uma proposta interessante para promover a leitura de questões clínicas e fenômenos sociais.

Retomando trabalhos em metodologia psicanalítica mais próximos ao contexto acadêmico brasileiro, encontramos nos autores brasileiros posições sobre a ciência nas quais o objeto científico não é natural, sendo criado pelo pesquisador com ajuda da lógica matemática (CALAZANS; SERPA, 2010). Guerra (2010) situa historicamente a possibilidade de existência da psicanálise em diálogo com a ciência. Ela expressa que o cartesianismo foi uma resposta à perda de certezas que deixou o Renascimento, a 
descoberta da imprensa e a laicização do Estado, entre outros. Daí que, com Descartes, a subjetividade se revela como obstáculo para acessar o conhecimento, mas ao mesmo tempo aparece como questão que antes não estava presente no horizonte, inaugurando uma condição de possibilidade para qualquer ciência da subjetividade (LACAN, 1966/1998b; GUERRA, 2010). Ao excluir a subjetividade do método cientifico, Descartes dá visibilidade ao sujeito. Para Guerra (2010), há um campo “nãorepresentacional que o inconsciente e as pulsões revelam e que extrapola completamente o projeto cartesiano de domínio da verdade pela consciência" (GUERRA, 2010, p. 137) Assim, o analista que participa da produção científica parte de um saber que escapa à universalização, está ciente de que qualquer produção acadêmica ao abordar o real ${ }^{4}$ parte de um ponto não recuperável que não será recoberto por esse saber, menos afeito ao modelo binário de aceitação/refutação e mais coerente com a perspectiva da multideterminação e da sobreposição, propenso a romper com a lógica da contradição (GUERRA, 2010).

Nesse sentido, surge a pergunta pelo caminho escolhido pela psicanálise para sustentar uma relação com a ciência. Se a psicanálise chegasse a se alienar à dinâmica de refutação de hipótese que a ciência moderna introduziu - e que se manifesta no mundo contemporâneo em outras formas de abordagem metodológica que conservam a defesa da evidência - teria duas opções: refutação ou aceitação. Na primeira, suas teorias desaparecem do panorama ao serem refutadas (refutação) e, na segunda, perdem a caraterística de ser psicanalíticas, pois, ao serem aceitas pelo método experimental, as teorias passariam a ser de domínio do campo universal, abandonando a ética da psicanálise de escuta do sujeito e extração da sua radical singularidade, deixando de lado o trabalho mesmo que implica levar em conta o inconsciente.

Se por um lado, a descoberta do inconsciente revela algo que escapa à racionalidade e o pesquisador "deve" ter respeito pela "significação a posteriori", por outro, o método científico moderno buscava uma forma segura e confiável de produzir conhecimentos (MOREIRA, 2010). Em consequência, a psicanálise não tem lugar no

\footnotetext{
4 "O Real" é uma concepção lacaniana que constitui, junto com "o simbólico" e "o imaginário", os três registros do inconsciente. É utilizada por Lacan desde suas primeiras obras e no final de seu ensino tem um protagonismo especial. Dunker (2015) expressa que "o Real é, no fundo, o nome para uma experiência perdida (o objeto, a Coisa, "a" relação sexual, a totalização do gozo), mas que, não obstante, incide na constituição do sujeito" (DUNKER, 2015, p. 102-103). Mas, esse real excede a potência de imaginação e simbolização do sujeito e se apresenta na clínica em formas de angustia e de ato (DUNKER, 2015). Em suma, o real é o nome que a psicanálise lacaniana dá para esse campo que faz que seja impossível a representação por completo da experiência inconsciente por vias simbólicas e imaginárias.
} 
método científico tradicional, pois não trabalha de acordo com certezas e com um ideal de recobrimento absoluto do real pelo sentido. Pode a psicanálise sustentar uma relação com a ciência?

Para Calazans e Serpa (2010) a ciência não tem um método geral: "Haverá tantos métodos quantos forem necessários para a produção de um objeto cientifico a partir de um problema científico" (p. 88) Mas como asseguram depois, o campo da psicanálise é mais a clínica que a ciência, pois o método da própria psicanálise é a clínica como uma experiência da fala. A psicanálise tem lugar na ciência enquanto preserve e consiga formalizar duas ferramentas da sua fundação como campo: o olhar clínico para a singularidade do sujeito e a premissa do inconsciente como registro impossível de ser representado inteiramente.

Se partimos da premissa de que a psicanálise pode dialogar com a ciência tradicional representada na universidade, participando do espaço de construção do saber acadêmico sobre seu objeto, que no caso da psicanálise é um saber não-todo em tanto ele parte da falta estrutural do sujeito que indica sua impossibilidade - qual é o lugar que corresponde à psicanálise na universidade, especificamente?

Freud (1919/1976) situou o que ele considerava era a relação que a psicanálise poderia ter com a universidade. Ao surgir fora do contexto universitário (excluída, como vimos, pois, Freud foi rejeitado pelos círculos acadêmicos da sua época), a psicanálise se deu a liberdade de questionar sua própria presença nos centros acadêmicos. Como diz Freud, a psicanálise pode prescindir da universidade sem qualquer prejuízo para si mesma, ela pode obter a teoria da literatura especializada e a prática a adquire na própria análise e na supervisão dos tratamentos que faz com "psicanalistas reconhecidos" (FREUD, 1919/1976). Para ele, a universidade é prescindível para a psicanálise.

Ainda assim, não se pode ignorar o fato de que dificilmente um psicanalista exerce algum tipo de atendimento, ou propicia uma experiência analítica sem possuir algum diploma nas ciências humanas (psicologia, sobretudo) ou na medicina, ainda quando há exceções. Por mais que a psicanálise encontre seu lugar de formação, supervisão e clínica nas sociedades psicanalíticas, escolas e nos institutos, continua atuando na universidade. A psicanálise resiste a ficar fora do meio universitário e a pesquisa acadêmica usufrui também algo da psicanálise, como veremos no final.

\section{Indissociabilidade da psicanálise e fenômenos sociais: pesquisar fora da experiência analítica?}


Depois de pensar no que a psicanálise discute sobre seu estatuto científico e da relação que ela tem com a universidade e com a produção de saber, é importante voltarmo-nos para um tema essencial que motivou a presente reflexão: o estatuto da pesquisa de fenômenos sociais. A questão dos fenômenos sociais deixa mais uma variável a resolver. De acordo com Freud (1922-23 apud MOREIRA, 2010) existe uma insociabilidade entre teoria, clínica e método, pois a psicanálise é definida como um procedimento de investigação, um procedimento terapêutico e uma teoria conceitual que continua em expansão e reformulação. Em 1919, Freud (1919/1976) indica que pesquisa e tratamento coincidem, mas depois de um tempo a técnica exigida por uma opõe-se à requerida pelo outro, e recomenda não incluir na pesquisa um caso quando o tratamento está caminhando.

Isso parece deixar a pesquisa em psicanálise restrita na sua dimensão clínica e de forma a posteriori, quando concluir o tratamento. De fato, muitos circuitos psicanalíticos ou universitários expressam que a pesquisa em psicanálise só pode partir da clínica ou, no outro extremo, que só é possível produção acadêmica da psicanálise quando esta seja teórica (GARCIA-ROZA apud COUTO, 2010). Mas Freud (1919/1976) advertia que a psicanálise não é só restringida, na sua versão investigativa, aos aspectos da clínica:

\section{A psicanálise segue seu próprio método específico. A aplicação desse método não está de modo algum confinada ao campo dos distúrbios psicológicos, mas entende-se também à solução de problemas da arte, da filosofia e da religião (FREUD, 1919/1976, p. 248).}

De acordo com Moreira (2010) o próprio Freud pesquisa fenômenos sociais assim como ficou discutido em Psicologias dos grupos de 1921. De fato, ela considera que a pesquisa em psicanálise não é exclusiva dos psicanalistas, pode "fundamentar-se em conceitos dessa teoria para produzir uma reflexão sobre algum fenômeno, sem, necessariamente, ser psicanalista” (p. 147).

Se seguimos a Freud em diferentes momentos da sua obra quando explora outros campos diferentes à clínica das "psiconeuroses", como por exemplo em Mal-estar na civilização, Psicopatologia da vida cotidiana e Psicologia dos grupos e análise do eu, podemos encontrar que o mesmo Freud abriu a possibilidade para a psicanálise dialogar com outros campos do saber por fora da atuação clínica. Fica claro que a pesquisa em psicanálise pode transitar por outros campos diferentes à experiência analítica ou ao atendimento da psicologia clínica orientada pela psicanálise. 
É importante propor uma advertência. Se existe pesquisa de fenômenos sociais em psicanálise sem intermediação clínica esta deve cumprir uma condição importante: ter no horizonte que o sujeito de qualquer pesquisa em psicanálise é o sujeito do inconsciente, marcado pela castração, pela cisão fundamental da linguagem e pela impossibilidade do real. Como diz Guerra (2010) é sobre essa leitura que uma pesquisa pode ser feita, pois esse sujeito não se apresenta apenas na clínica. Como vimos com Freud (1933b/1976) o psicanalista não consegue retirar seus óculos de psicanalista de forma seletiva.

Nesse sentido, poderíamos afirmar, segundo uma leitura de Freud, de Lacan e das proposições da psicanálise lacaniana, que a pesquisa em psicanálise na universidade, seja de fenômenos sociais, teórica ou clínica sustenta-se na perspectiva do sujeito do inconsciente. Isso implicaria que o objeto de pesquisa se constrói com o campo no qual se efetua a pesquisa ou com a qual ela dialoga, seja as artes, a política, os fenômenos sociais, a medicina, etc., mas conseguindo enxergar esse sujeito (do objeto de pesquisa) pela tríade que o constitui: inconsciente-corpo-linguagem.

No que refere especificamente ao lugar da pesquisa de fenômenos sociais, Rosa (2014) constrói uma reflexão interessante. Para a autora, a pesquisa de fenômenos sociais pertence à psicanálise em extensão, onde se tem um sujeito ligado a fenômenos sociais que o implicam e não somente ao tratamento. Embora, ela expressa que este tipo de pesquisa não tem sido excluído de críticas no interior da psicanálise como, por exemplo, a acusação de que este tipo de pesquisa fica fora dos objetos do campo das descobertas freudianas. A autora responde a essa crítica expressando que o inconsciente está presente como determinante nas mais variadas manifestações humanas, culturais e sociais (ROSA, 2014).

Uma das críticas que mais ressalta Rosa (2014) é que se diz que neste tipo de pesquisa os dados não vêm de material inconsciente nem de associação livre, ficando a interpretação como um ato selvagem fora do dispositivo analítico. Ela ressalta que o próprio Freud testemunha uma possibilidade da psicanálise em extensão e retoma Lacan para indicar que, com ele, abre-se a possibilidade de que a análise da fala possa ser feita pela vertente dos discursos que produzem uma certa forma de laço social, articulando-se às especificidades do fenômeno.

Como ela diz, este tipo de pesquisa permite um avanço na teoria psicanalítica, pois partem do fenômeno ao conceito, e o analista, tal qual como sucede numa análise, deve estar ao serviço da questão contingente que se apresenta: "A observação dos fenômenos, 
está em interação com a teoria, produzindo o objeto de pesquisa, não dado a priori, mas produzido na e pela transferência" (ROSA, 2004, p. 341).

Nesse aspecto coincidem Gallo e Ramirez (2012). Os autores descrevem que as categorias emergem a partir de um "ponto de saturação" que indica estabelecer uma variável fixa, na qual, apesar da troca do tamanho da mostra, por mais entrevistas que sejam feitas, sempre se chega ao mesmo ponto, o que permite estabelecer umas categorias de análise. A psicanálise vai mais além disso pois toma em consideração os signos do gozo (a manifestação da forma como o sujeito lida singularmente com uma falta universal da sua constituição), que indicam o prazer ignorado pelo mesmo sujeito (GALLO; RAMÍREZ, 2012). É a partir disso que se constituem as categorias emergentes, o que não difere muito do método de chave ou da experiência, proposto por Lacan em seu Seminário sobre $A$ angústia:

\footnotetext{
Aquilo que abre e que para abrir, funciona... isto é para mim a função da análise, que tem em si mesma uma função de saber. A chave é a forma pela qual funciona ou não a função significante como tal. Nela se pode "confiar" ... nada "é marcado pela presunção" (LACAN, 1962-63/2005, p. 30).
}

Além disso, pesquisa psicanalítica e intervenção, inclusive nos fenômenos sociais, não está desligada ou localizada em campos distintos. Para Rosa (2014), a escuta psicanalítica é transgressora em relação aos fundamentos da organização social: dessa escuta não se sai isento, escuta-se de um lugar que rompe barreiras de um sujeito indicado a partir de seus predicados.

A própria produção do conhecimento sobre o campo social não é em si mesma uma forma de intervenção ao desvelar o saber sobre do fenômeno social? Para podermos responder a essa pergunta, será necessário recorrer à teoria dos discursos proposta por Lacan.

\section{Laço social como discurso}

É indispensável situar o que estamos entendendo por discurso como forma de laço social na psicanálise de orientação lacaniana, pois isso dará luzes para entender as lógicas de poder e a potencialidade subversiva que implica pesquisar em psicanálise dentro da universidade.

O laço social como discurso foi desenvolvido por Lacan no Seminário: $O$ avesso da psicanálise, no qual Lacan (1969-70/1991) expressa que se trata de um discurso sem 
palavras, que mediado pela linguagem inscreve relações estáveis. Lacan faz uso da formalização matemática utilizando quatro elementos como:

$\mathrm{S}_{1}$, que faz referência ao significante mestre:

$\mathrm{S}_{2}$, como o saber e a bateria dos significantes, onde se fixa o discurso;

$a$, como objeto causa de desejo e;

$\$$, como o sujeito barrado do inconsciente.

Esses quatro elementos configuram um discurso na medida em que se inscrevem em alguma de estas posições:

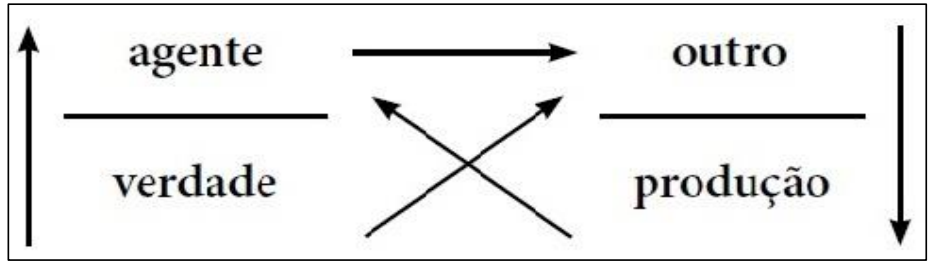

Figura 1: Relação entre elementos do discurso

Fonte: Lacan (1969-70/1991)

É importante entender que na visão de Lacan, o inconsciente está estruturado como uma linguagem, no qual a relação de significantes em uma cadeia produz o significado, mas essa significação só tem sentido quando um significante se coloca em relação ao resto dos significantes na cadeia, pois não existe sentido no interior de um significante isolado. O significante-mestre é um operador que permite entender que existe algum significante que orienta o resto da cadeia, denominado por Lacan como $\mathrm{S}_{1}$, sendo o significante que dá legibilidade ao discurso e aquele que se coloca no comando da cadeia (LACAN, 1969-70/1991). Assim, a cadeia estaria organizada com um $\mathrm{S}_{1}, \mathrm{~S}_{2}, \mathrm{~S}_{3}$, $\mathrm{S}_{4}$, etc.

Lacan (1969-70/1991) elabora uma teoria sobre o laço social, que contribui a ler questões de dominação e poder, tomando como referência essa visão do inconsciente. Nessa teoria o laço social está organizado como um discurso que se rege pela relação dos elementos mencionados acima $\left(\mathrm{S}_{1}, \mathrm{~S}_{2}, a, \$\right)$. Cada forma de laço social ou discurso está comandada por um elemento, seja o significante mestre $\left(S_{1}\right)$, o saber $\left(S_{2}\right)$, o gozo do sujeito representado pelo objeto $a$, ou o próprio sujeito $(\$)$. Nesse sentido, retomando a figura anterior, o agente representa o que motiva o discurso, o outro é aquele ao que se dirige o discurso, que produz algo (produção) e que sustenta uma impotência entre a produção e a verdade, pois a verdade sempre está barrada e só se pode dizer pela metade (LACAN, 1969-1970/1991). 
Para Lacan (1969-70/1991) existe uma relação primitiva entre gozo e saber, pois, o saber do inconsciente, que é o alvo de uma análise, é um saber parecido ao que Lacan considera como um savoir-faire $e^{5}$ ancestral. Existe no inconsciente um saber que faz com que a vida se detenha em um certo limite em direção ao gozo, que é o caminho à morte. O discurso do inconsciente, como forma de manifestação do discurso do mestre, e o discurso do analista é o avesso do discurso do mestre, pois vai em direção oposta à forma como se constitui esse saber mais arcaico. O discurso do mestre se define da seguinte maneira:

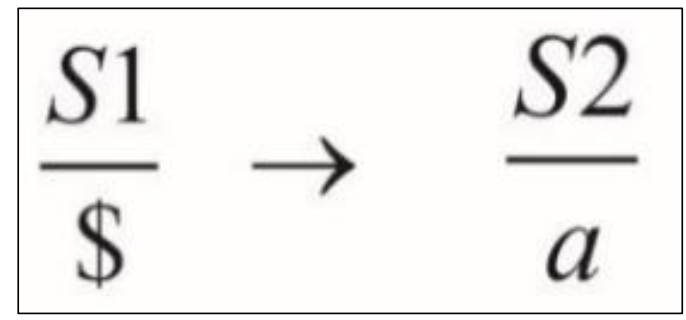

Figura 2: Discurso do mestre

Fonte: Lacan (1969-70/1991)

Este discurso foi pensado por Lacan baseando-se na lógica do senhor e o escravo do Hegel, pelo qual o discurso tem um efeito de dominação, de um mestre sobre o saber do escravo (neste caso) e produz um excedente como mais-de-gozar. O que o discurso elucubra como verdade é que o mestre é castrado, pelo qual também é um sujeito barrado (LACAN, 1969-70/1991). Dito isso, o discurso sempre tem um elemento dominante, no caso desse discurso é o mestre enquanto $S_{1}$. Esta seria a forma de laço social clássica e que serve para ler tanto a estrutura do inconsciente como a política e as formas de dominação. Em síntese, nesse discurso existe um significante mestre que se dirige a outro significante, produzindo um excesso de gozo, e um perda desse gozo representada pelo objeto $a$.

As outras possibilidades que elabora Lacan (1969-70/1991), são o discurso do universitário, o discurso da histérica e o discurso do analista, como fica desenhado na seguinte figura:

\footnotetext{
${ }^{5}$ Em português esta expressão significa saber-fazer, que é entendida por Lacan (1969-70/1991) com uma forma de saber que acontece no ato, com uma lógica parecida à lógica do instinto na qual o indivíduo "sabe" responder por meio da ação a um estimulo particular. $\mathrm{O}$ que o autor propõe é que o ser humano ao não contar com o instinto (o saber-fazer que os animais têm), produz um saber-fazer por meio da incidência do inconsciente que supre sua essa carência constitutiva.
} 


\begin{tabular}{|cc|}
\hline $\begin{array}{cc}\text { Discurso do Mestre } \\
\mathrm{S} 1\end{array}$ & Discurso Universitário \\
Discurso da Histérica & $\frac{\mathrm{S} 2}{\mathrm{~S} 1} \rightarrow \frac{\mathrm{a}}{\mathrm{S}}$ \\
$\frac{\$}{\mathrm{a}} \rightarrow \frac{\mathrm{S} 1}{\mathrm{~S} 2}$ & Discurso do Analista \\
\hline
\end{tabular}

Figura 3: Os quatro discursos

Fonte: Lacan (1969-70/1991)

Discurso universitário. Para Lacan o que domina no discurso universitário é o $\mathrm{S}_{2}$ como saber que se dirige a um objeto ( $a$, representando os objetos de estudo da ciência) e que produz um sujeito (\$), equiparável ao sujeito da ciência.

- Discurso da histérica. A histérica (\$) fabrica um homem movido pelo desejo de saber. Ela se dirige a um outro que é tomado como mestre $\left(S_{1}\right)$, gerando nele um furo do saber dele como mestre $\left(S_{2}\right)$ a través de seu sintoma indecifrável como elemento dominante representado nela como sujeito dividido (\$), (LACAN, 196970/1991). Retoma a lógica do movimento que fizeram as histéricas sobre Freud, gerando nele desejo de um novo saber sobre a etiologia da histeria no século XIX.

- Discurso do analista. Lacan o menciona como uma histerização do discurso: "é a introdução estrutural, mediante condições artificiais, do discurso da histérica" (LACAN, 1969-70/1991, p. 31). Ele se dirige do analista como rechaço da causa de desejo (objeto $a$ ) a um sujeito barrado (\$), produzindo um novo tipo de significante mestre. Interessante que no lugar da verdade está o saber, o que significa que a verdade é tomada como um enigma; ela nunca se pode dizer senão pela metade, "um saber como verdade é aquilo que define por estrutura o que se chama uma interpretação (LACAN, 1969-70/1991, p. 34). O discurso do analista, diferente dos outros, toma o outro como sujeito e produz nele alguma posição diferente à dominação do mestre em tanto reconhece que ele é um sujeito divido pela incidência do inconsciente.

Para distinguir o que mobiliza os quatro discursos de forma particular podemos entender o elemento que domina em cada um deles e que está localizado no lugar do agente (lado superior esquerdo). No discurso do mestre seria a Lei, tomada como $\mathrm{S}_{1}$, no caso da histérica é o sintoma que é consequência de ser um sujeito barrado (\$), no caso 
do analista é o rechaço à posição como causa de desejo do Outro ${ }^{6}$ representado em $a$ e no universitário é o saber representado no S $_{2}$ (LACAN, 1969-70/1991).

Uma versão contemporânea do discurso do mestre aparece posteriormente a esse seminário, e seria o discurso capitalista, elaborado posteriormente por Lacan em 1972:

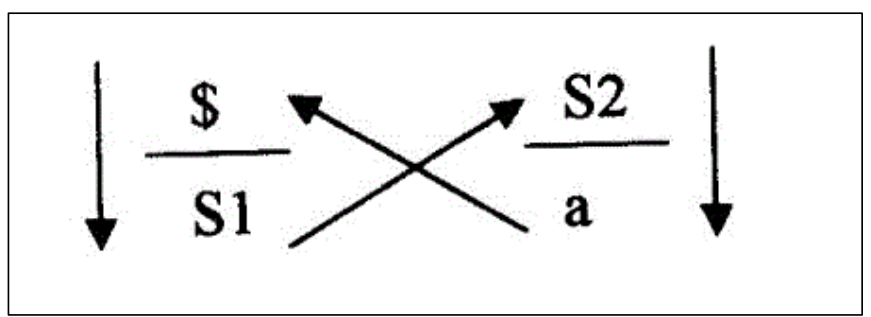

Figura 4: Discurso capitalista

Fonte: Lacan (1972)

Trata-se de uma versão subvertida do discurso do mestre, que evidencia um discurso fraco que não faz laço social. Nele o sujeito atua como agente, mas numa relação direta com o objeto $a$, que representa os objetos de consumo e a tentativa do sujeito para obturar sem sucesso a falta estrutural. O saber da ciência $\left(S_{2}\right)$ tem uma relação direta com o mestre do capitalismo $\left(S_{1}\right)$, o que evidencia uma parceria entre ciência e capitalismo que produz gadgets de consumo (LACAN, 1969-70/1991; LACAN, 1972). Como se vê, ele não contém a relação da cadeia significante $\left(S_{1}-S_{2}\right)$, pelo qual é um discurso que não faz laço social.

\section{0 que fica no intercâmbio: a subversão de discursos}

Expostas as bases da teoria lacaniana dos discursos, cabe agora explorar como essas formas de fazer laço social que sustentam a universidade, a psicanálise e o campo social se veriam implicadas na pesquisa psicanalítica de fenômenos sociais. Previamente mostramos que algumas posições psicanalíticas não contemplam a possibilidade da pesquisa de fenômenos sociais. Mas, encaramos esse impasse pensando que o inconsciente produz conteúdo não só na experiência analítica, podendo-se pesquisar fora da prática clínica, sem se retirar o olhar psicanalítico do fenômeno. Ainda quando não se esteja intervindo, a escuta, como foi proposta por Freud, tem uma potencialidade de

\footnotetext{
${ }^{6}$ Operador lógico na teoria lacaniana que remete a uma alteridade que constitui o sujeito. O grande Outro (com maiúscula) é diferente do outro com minúscula que equivale ao semelhante. O grande Outro faz uma mediação entre sujeito e seu semelhante (outro), pois é a integração que o sujeito faz da linguagem e possui uma bateria significante da qual se serve para construir seu registro simbólico.
} 
intervenção importante para os sujeitos, como acontece no âmbito de uma entrevista para uma pesquisa.

A potencialidade de cada pesquisa de fenômenos sociais vai depender da responsabilidade ética e do rigor $^{7}$ do pesquisador psicanalista. Mas a pesquisa de fenômenos sociais teria uma possibilidade de intervenção no social em duas vias. A primeira, no sujeito que participa da pesquisa, pois a escuta que inaugurou Freud tem uma possibilidade de desvelar algo de si partindo somente da produção discursiva do sujeito no momento de falar e a orientação que o psicanalista pesquisador faz por meio da escuta. O segundo aspecto está dirigido à leitura do social em geral, apontando o fato de que o saber sobre o social e o político que se produz tem uma potencialidade transformadora. Como diz Alberti (2010), o pesquisador psicanalista pode fazer girar os discursos que geram laço social, e pode fazer uma contribuição da psicanálise no laço social contemporâneo ao revelar as consequências devastadoras do discurso capitalista.

Pesquisar fenômenos sociais com um olhar psicanalítico no interior de instituições universitárias tem consequências subversivas nas formas hegemônicas de poder para o saber universitário, as instituições de psicanálise e o campo social, tendo uma potencialidade política em fazer girar as lógicas internas de cada um desses campos. Vejamos como.

Em relação às incidências do intercâmbio com a universidade podemos pensar que, ao sustentar a singularidade como premissa fundamental, a psicanálise contribui para fazer resistência contra discursos hegemônicos e prescritivos do fazer ciência. A psicanálise fica como uma disciplina subversiva que não se alienou à lógica da revolução científica (PINTO, 1999 apud NETO, 2010). Nesse sentido, podemos pensar que a psicanálise subsiste e não é substituída por outra teoria que aborde o mesmo objeto, porque não tenta impor um outro paradigma como é característico na revolução científica (KUHN, 1983), refutar uma teoria ou dar um valor de verdade sobre seu objeto de estudo. A psicanálise não opera com uma intenção de revolução científica, nem com o discurso da universidade, no qual existiria uma soberania de um saber científico sobre outro. Ela fica no plano do subversivo pois entende a revolução como retorno ao mesmo ponto, qual seja, a produção de um novo mestre, de um novo ideal. Ela opera com o discurso analítico e que se comprova na clínica. É quiçá isso o que faz que ideias exploradas por Freud há mais de cem anos se sustentem no decorrer dos anos.

\footnotetext{
${ }^{7} \mathrm{O}$ rigor do pesquisador na psicanálise o colocamos mais do lado do cuidado do analista ou pesquisador psicanalista por preservar o sujeito do inconsciente que no campo prescritivo de tarefas a seguir.
} 
Além disso, Calazans e Serpa (2010 expressam que no momento em que se sustenta o discurso analítico na instituição algo da lógica institucional se vê subvertida. Por isso, é necessário introduzir o sujeito da palavra, ou seja, introduzir o particular no universal da instituição. A psicanálise realiza, assim, uma função política na universidade. Ao ser sempre subversiva por constituição, incomoda o discurso universitário, mas se serve dele para subverter a verdade absoluta que a universidade tenta sustentar, fazendo emergir o sujeito do inconsciente que foi foracluido historicamente do plano cientifico, valendo-se de uma das versões do sujeito da ciência (o psicanalista pesquisador na universidade) e não do método como caminho rígido.

Calazans e Serpa (2010) mencionam que os professores universitários pesquisadores em psicanálise se encontram envolvidos numa resposta ao duplo vínculo: ao discurso psicanalítico como analistas e ao universitário como professores. Esse duplo vínculo marca tensão, pois o discurso universitário responde à avaliação à qual é submetido o pesquisador, os programas de pós-graduação e as próprias universidades, e a prática analítica responde a outras lógicas de validação.

Alberti (2010) sublinha que o saber da psicanálise é muito particular, pelo qual a psicanálise não se transmite como qualquer outro saber, pois a formação analítica para exercer a clínica não acontece na universidade: a universidade não forma analistas. Por tanto, a função da psicanálise na universidade é também relativizar a própria questão do saber. Para a autora, a psicanálise na universidade ocupa um lugar especial:

\footnotetext{
Já não seria o lugar para um trabalho em transferência - o da psicanálise propriamente dita -, mas um lugar em que a transferência de trabalho permite persistir na produção da psicanálise como discurso que subverte - em recuo o discurso dominante (ALBERTI, 2010, p. 124).
}

Inclusive, a psicanálise pode fazer girar os discursos para os fins que são aqueles da escola de psicanálise: "divulgar a psicanálise garantindo sua presença no mundo" (ALBERTI, 2010, p. 125)

Para Guerra (2010), essa tensão universidade-psicanálise se arraiga no fato de que a universidade visa a universalização e a psicanálise conta com a contingência como fator imprescindível. E a pesquisa em psicanálise teria esse elemento diferencial de questionar as próprias formas de laço social promovidas no tempo contemporâneo, assim como a própria produção científica, alienada aos ideais e interesses de sua época.

Como acréscimo, o alvo ou lugar comum entre psicanálise e universidade é a pesquisa (MOREIRA, 2010). A pesquisa psicanalítica poderia ser entendida, segundo ela, como um conjunto de atividades que produzem um conhecimento que pode ter com 
a psicanálise relações diversas. Mas a universidade também pode legitimar a vocação cientifica da psicanálise (PINTO, 1999, apud MOREIRA, 2010). Não podemos esquecer que o fundador da psicanálise tinha para ela projetos de cientificidade e de inserção na visão do mundo que a ciência e a universidade, como instituição que faz ciência, constrói.

Mas, nessa visão do mundo científica na qual a psicanálise poderia ocupar um lugar, há que identificar a particularidade do pesquisador psicanalítico. O que singulariza o pesquisador analítico é o campo de estudo: o inconsciente. Pela mesma natureza do inconsciente, o pesquisador psicanalítico "deve ser crítico de uma proposta que busca uma visão de mundo totalizada" (MOREIRA, 2010, p. 151). O inconsciente implica uma singularidade que emerge na leitura do sujeito e uma impossibilidade de prever, quantificar ou normatizar as produções do inconsciente. O inconsciente é susceptível de leitura e formalização a partir da contingência, mas não é suscetível de universalização.

Imersa na Weltanschauung da ciência, a psicanálise deve delimitar sua própria característica que a exclui de ser uma Weltanschauung particular, como chegou a problematizar Freud. A psicanálise se situa de forma interna e externa em relação à ciência, tal qual a banda de Moebius ${ }^{8}$. Assim, a função da psicanálise face ao próprio campo científico é a de subverter a ciência, fazê-la encontrar sua impossibilidade de totalizar uma visão do mundo, de recobrir de sentido por completo o real. É quiçá pelo caráter subversivo que a psicanálise e o sujeito do inconsciente carregam em relação ao saber absoluto da ciência, que a psicanálise tem sido historicamente convocada a ficar fora do saber universitário, com ou sem sucesso.

Mas a universidade não somente se "beneficia" desse encontro entre discurso universitário e discurso analítico. Neto (2010) afirma que a universidade por pretender diversidade (e exigindo um espírito crítico e uma coerência ao analista) pode ser um antídoto para o discurso do mestre presente em algumas instituições de psicanálise. $\mathrm{O}$ discurso universitário versa sobre a estabilidade e a coerência. O discurso analítico tem a ver com a falta, com aquilo que não se deixa apreender.

\footnotetext{
${ }^{8}$ É uma figura geométrica em forma de fita desenvolvida por August Fernand Moebius em 1858, organizada de forma tal que se alguém passa o dedo pela superfície da fita vai conseguir passar da parte externa à interna sem perceber (PEDREGAL, 2007). É uma figura que, a diferencia do que indica uma percepção primeira, não tem dois bordes, senão um que compõe o interior e exterior ao mesmo tempo (PEDREGAL, 2007). O recurso da fita de Moebius é utilizado por Lacan para questionar as ideias do interno e o externo na própria psicanálise para entender a lógica da constituição do sujeito como algo mais interativo e a relação complexa da inclusão da psicanálise na ciência.
} 
A transmissão da psicanálise na universidade pode estar em uma posição mais privilegiada na luta com os efeitos tóxicos do saber ${ }^{9}$, pensados agora em relação às escolas e demais instituições psicanalíticas (PINTO, 1999, apud NETO, 2010). A psicanálise poderia possibilitar superar a transferência do analista com sua instituição de origem (as escolas, institutos e sociedades onde realiza sua formação clínica), questionar os laços corporativos com essas instituições e legitimar a autoria do psicanalista (NETO, 2010).

Recordemos que o progresso da psicanálise com Freud e com Lacan se deu graças à leitura crítica que estes autores introduziram na própria disciplina a partir de outras leituras externas. A psicanálise se valeu de outros campos do saber para avançar. Com Freud, isso aconteceu em muitos momentos; quando ele utiliza a arte para analisar sonhos; quando utiliza o mito para compreender a gênese das neuroses; quando explora na antropologia o desenvolvimento das sociedades exogâmicas; ou quando analisa as massas humanas para avançar em sua teoria da identificação. A montagem da psicanálise lacaniana, não teria sido possível se seu "retorno a Freud" tivesse excluído a linguística de Saussure e o estruturalismo, acompanhado da compreensão antropológica de Levi Strauss.

Parece que a psicanálise avança quando sai dela mesma e toma leituras externas, para depois voltar a se servir delas e restabelecer tanto sua coerência interna quanto as possibilidades que seus conceitos alcançam para ler seu objeto de estudo. Isso só pode acontecer em um intercâmbio fornecido pela produção dos outros saberes, que acontece na universidade. $\mathrm{O}$ enlace entre psicanálise e o saber universitário parece ser uma condição que contribui ao avanço da psicanálise e do saber universitário para se questionar sobre sua impossibilidade de recobrir o real pelo sentido e a razão.

Pesquisar fenômenos que chamamos "sociais" implica enfim mais uma subversão. Como diz Rosa (2014), partindo da reflexão de Lacan no Seminário 17, existe um sintoma social que é uma forma do laço social do capitalismo e que se apresenta como fenômenos sociais que são pesquisados dentro da psicanálise. Assim, a pesquisa psicanalítica também faz uma revelação desses sintomas sociais produzidos pelo discurso do capitalismo, evidenciando as implicações de dito discurso no plano social e sua própria falha ao enfraquecer o laço social e produzir novas e inéditas formas de sofrimento.

\footnotetext{
${ }^{9}$ Crítica à reprodução dogmática de saberes que pode ser entendida como a "Repetição de uma teoria descolada de uma reflexão sobre seus efeitos e sua interface com as questões da sociedade contemporânea" (PINTO, 1999, apud NETO, 2010)
} 


\section{Considerações finais}

Pesquisar fenômenos sociais com um olhar psicanalítico no interior da universidade contemporânea precisa não somente descrever os métodos, as técnicas e as referências conceituais que vão ser úteis para formalizar os objetos de estudo. O histórico de tensões no intercâmbio entre universidade e psicanálise torna necessária toda uma reflexão sobre as condições para esse tipo de pesquisa.

O trabalho de construir um saber sobre essa problemática evidenciou que no fundo dessas tensões existem questões políticas que indicam lógicas diferenciadas de poder no campo da universidade, do social e da psicanálise. Nessa forma de pesquisa que toma os fenômenos sociais como recorte de objeto se entrelaçam esses elementos e se produzem alterações em cada lógica.

Segundo a leitura desses campos regidos por formas de laço social que Lacan (1969-70/1991) denominou de discursos, e retomando a reflexão de pesquisadores da psicanálise com trajetória reconhecida em pesquisa, pensamos que o intercâmbio que se produz tem efeitos subversivos que indicam uma potencialidade política pois fazem barreira às formas de dominação presentes na universidade com o discurso universitário, no social com o discurso capitalista e em algumas instituições de psicanálise com o discurso do mestre. Isso deslocaria as lógicas de cada forma de dominação desses discursos e permitiria avanços, reflexões, ajustes e a consolidação de uma linha de pesquisa crítica.

Em síntese, a universidade, os psicanalistas e a leitura crítica do campo social poderiam se servir do intercâmbio que essa modalidade de pesquisa propõe para tomar algo interessante para seu campo; a universidade estaria em constante questionamento sobre os limites dos métodos científicos universais, levando em consideração a singularidade como campo de estudo possível; os analistas teriam presente uma postura crítica frente a suas instituições de origem; e o saber sobre os fenômenos sociais, ao sair da universidade, impactaria as formas de ler a estrutura social.

\section{Referências}

ARBISER, S. Psicoanálisis en argentina. Revista Uruguaya de Psicoanálisis, Montevideo, n. 97, p. 159-181, 2003.

ALBERTI, S. Pesquisa e transmissão da psicanálise no contexto universitário. In: KYRILLOS, NETO F.; MOREIRA, J. (Orgs.). Pesquisa em psicanálise: transmissão na universidade. 1. ed. Belo Horizonte: Barbacena EdUEMG, 2010. p. 113-129. 
CALAZANS, R.; SERPA, T. Psicanálise e método científico: pesquisa de campo. In: KYRILLOS, NETO F.; MOREIRA, J. (Orgs.). Pesquisa em psicanálise: transmissão na universidade. 1. ed. Belo Horizonte: Barbacena EdUEMG, 2010. p. 81-98.

CAPES (Coordenação de Aperfeiçoamento de Pessoal de Nível Superior). Documento de área: psicologia. Brasil, 2016. Disponível em:

$<$ http://capes.gov.br/images/documentos/Documentos_de_area_2017/PSIC_docarea_15fev2017 .pdf $>$. Acesso em: 25 jan. 2018

COUTO, L. F. Quatro modalidades de pesquisa em psicanálise. In: KYRILLOS, NETO F.; MOREIRA, J. (Orgs.). Pesquisa em psicanálise: transmissão na Universidade. 1. ed. Belo Horizonte: Barbacena EdUEMG, 2010. p. 59-80.

DUNKER, C. I. L. Mal-estar, sofrimento e sintoma. 1. ed. São Paulo: Boitempo Editorial, 2015.

FREUD, S. Cinco lições de psicanálise (trabalho original de 1909-1910). In: FREUD, S. Edição standard das obras completas de Sigmund Freud, Vol. XI. 1. ed. Rio de Janeiro: Imago, 1976. p. 26-75.

FREUD, S. Recomendações aos médicos que exercem a psicanálise (trabalho original publicado em 1912). In FREUD, S. Edição standard das obras psicológicas completas de Sigmund Freud, Vol. XII. 1. ed. Rio de Janeiro: Imago, 1976. p. 123-133.

FREUD, S. A história do movimento psicanalítico (trabalho original publicado em 1914). In: FREUD, S. Edição standard das obras completas de Sigmund Freud, Vol. XIV. 1. ed. Rio de Janeiro: Imago, 1976. p. 77-81.

FREUD, S. Sobre o ensino da psicanálise nas universidades (trabalho original publicado em 1919). In: FREUD, S. Edição standard das obras completas de Sigmund Freud, Vol. XVIII. 1. ed. Rio de Janeiro: Imago, 1976. p. 217-220.

FREUD, S. Psicologia de grupo e análise do ego (trabalho original publicado em 1921). In: FREUD, S. Edição standard das obras completas de Sigmund Freud, Vol. XVIII. 1. ed. Rio de Janeiro: Imago, 1976. p. 89-179.

FREUD, S. A questão de uma Weltanschauung (trabalho original publicado em 1933a). In: FREUD, S. Edição standard das obras psicológicas completas de Sigmund Freud, Vol. XXII. 1. ed. Rio de Janeiro: Imago, 1976. p. 193-220.

FREUD, S. Conferência XXXIV: explicações, aplicações e orientações (trabalho original publicado em 1933b). In: FREUD, S. Edição standard das obras completas de Sigmund Freud, Vol. XXII. 1. ed. Rio de Janeiro: Imago, 1976. p. 167-191.

GALLO, H.; RAMÍREZ, M. E. El Psicoanálisis y la investigación en la universidad. 1. ed. Buenos Aires: Grama, 2012.

GUERRA, A.M.C. Psicanálise e produção científica. In: KYRILLOS, NETO F.; MOREIRA, J. (Orgs.). Pesquisa em psicanálise: transmissão na universidade. 1. ed. Belo Horizonte: Barbacena EdUEMG, 2010. p. 130-145.

HALE, N. G. Jr. Freud in America, Vol. 2. The rise and crisis of psychoanalysis in the United States: Freud and the Americans, 1917-1985. 1. ed. New York: Oxford University Press, 1995. 
KUHN, T. La estructura de las revoluciones científicas. 5. ed. México D.F., México: Fondo de Cultura Económica, 1983.

LACAN, J. O seminário, livro 17. O avesso da psicanálise (1969-1970). 1. ed. Rio de Janeiro: Jorge Zahar Editor, 1991.

LACAN, J. O seminário, livro 11. Os quatro conceitos fundamentais em psicanálise (1964). 1. ed. Rio de Janeiro: Jorge Zahar Editores, 1998a.

LACAN, J. A ciência e a verdade (1966). In: LACAN, J. Escritos. 1. ed. Rio de Janeiro: Jorge Zahar Editores, 1998b.

LACAN, J. O saber do psicanalista. Seminário 1971-1972 (Publicação para circulação interna). Recife: Centro de Estudos Freudianos do Recife, 2000-2001.

LACAN, J. O seminário, livro 10. A angústia (1962-63). 1. ed. Rio de Janeiro: Zahar, 2005.

LAURENT, E. Alienação e separação II. In: FELDSTEIN, R.; FINK, B.; JAANUS, M. Para ler o seminário 11 de Lacan. Tradução de Dulce Duque Estrada. 1. ed. Rio de Janeiro, Brasil: Jorge Zahar Editores, 1997. p. 42-51.

MOREIRA, J. O. Pesquisa em psicanálise na pós-graduação: diferentes possibilidades. In: KYRILLOS, NETO F.; MOREIRA, J. (Orgs.). Pesquisa em psicanálise: transmissão na Universidade. 1. ed. Belo Horizonte: Barbacena EdUEMG, 2010. p. 146-155.

NETO, F. K. Psicanálise na universidade e sua relação com as instituições formadoras. In: KYRILLOS, NETO F.; MOREIRA, J. (Orgs.). Pesquisa em psicanálise: transmissão na universidade. 1. ed. Belo Horizonte: Barbacena EdUEMG, 2010. p. 156-166.

PEDREGAL, A.M. N. Quizás una cuestión de topología social: Moebius, la interculturalidad y los residentes europeos en Alicante. Revista Valenciana d'Etnologia, Valencia, n. 2, p. 33-58, 2007.

RABIVONICH, D. La angustia y el deseo del Otro. 1. ed. Buenos Aires, Argentina: Ediciones Manantial, 1993.

RICOEUR, P. O conflito das interpretações: ensaios de hermenêutica. 1. ed. Rio de Janeiro: Imago, 1978.

ROSA, M. D. A pesquisa psicanalítica de fenômenos sociais e políticos: metodologia e fundamentação teórica. Revista Mal-estar e subjetividade, Fortaleza, v. 14, n. 2, p. 329-348, ago. 2004.

SILVA, A. C. D. Os fundamentos freudianos e as aplicações da psicanálise: condições, possibilidades e implicações. 2012. 118 f. Dissertação (Mestrado em psicologia) -Setor de Ciências Humanas, Letras e Artes, Universidade Federal do Paraná, Curitiba, 2012.

STENGERS, I; CHERTOK, L. Le coeur et la raison. L'hypnose en question de Lavoisier à Lacan. 1. ed. Paris: Payot, 1989.

Recebido em: 31 de janeiro de 2018.

Aceito em: 17 de julho 2018. 